\title{
BMJ Open Examining satisfaction of older adult patients and their caregivers following traumatic injury: a cross-sectional study of three level I trauma centres
}

\author{
Rebecca Vogel, ${ }^{1}$ Constance McGraw, ${ }^{2,3,4}$ Alessandro Orlando, ${ }^{2,3,4}$ Pamela Bourg, ${ }^{1}$ \\ Chester Dreiman, ${ }^{1}$ Laura Peck, ${ }^{5}$ Allen Tanner, ${ }^{6}$ Neal Lynch, ${ }^{6}$ David Bar-Or (iD ${ }^{2,3,4}$
}

To cite: Vogel R, McGraw C, Orlando A, et al. Examining satisfaction of older adult patients and their caregivers following traumatic injury: a cross-sectional study of three level I trauma centres. BMJ Open 2019;9:e032374. doi:10.1136/ bmjopen-2019-032374

- Prepublication history and additional material for this paper are available online. To view these files, please visit the journal online (http://dx.doi. org/10.1136/bmjopen-2019032374).

Received 19 June 2019 Revised 18 September 2019 Accepted 15 October 2019
Check for updates

(C) Author(s) (or their employer(s)) 2019. Re-use permitted under CC BY-NC. No commercial re-use. See rights and permissions. Published by BMJ.

For numbered affiliations see end of article.

Correspondence to Dr David Bar-0r; davidbme49@gmail.com

\section{ABSTRACT}

Objective To explore satisfaction of care received by older adult patients and their primary caregivers following traumatic injury.

Design Prospective, cross-sectional study using the FAMCARE (Family Satisfaction with Advanced Cancer Care Scale) satisfaction surveys prior to discharge.

Setting Three level I trauma centres in Colorado from November 2016 to December 2017.

Participants Trauma patients $\geq 55$ years old and their primary caregivers.

Outcome measures Overall mean (SD) satisfaction, satisfaction $<80 \%$ vs $\geq 80 \%$, and mean satisfaction by survey conceptual structures.

Results Of the 319 patients and 336 caregivers included, the overall mean (SD) patient satisfaction was $81.7 \%$ $(15.0 \%)$ and for caregivers was $83.6 \%$ (13.4\%). The area with the highest mean for patient and caregiver satisfaction was psychosocial care $(85.4 \%$ and $86.9 \%$, respectively). Information giving was the lowest for patients $(80.4 \%)$ and caregivers (80.9\%). When individual items were examined, patients were significantly more satisfied with 'availability of nurses to answer questions' (84.5 (15.3) vs 87.4 (14.8), $p=0.02$ ) and significantly less satisfied with 'speed with which symptoms were treated' (80.6 (17.9) vs 84.0 (17.0), p=0.03) compared with caregivers. Patients with a history of smoking (least squares mean difference: -0.096 ( -0.18 to -0.07 ), $p<0.001)$ and hospital discharge destination to an outside facility of care (adjusted OR: 1.6 (1.0 to 2.4), $p=0.048$ ) were identified as independent predictors of lower overall satisfaction in generalised linear and logistic models, respectively.

Conclusions Our data suggest that patients' medical history was driving both patient and caregiver satisfaction. Patient characteristics and expectations need to be considered when tailoring healthcare interventions.

\section{INTRODUCTION}

The provision of patient-centred and familycentred medical care is well established in the published literature, with multiple studies highlighting the need for attention to experiences of both the patientand their family members. ${ }^{1-4}$ Particularly in older adult

\section{Strengths and limitations of this study}

- Satisfaction was examined by stratifying into scores of $\leq 80 \%$ vs $\geq 80 \%$ and also by overall mean (SD) satisfaction.

- The study measured both patient and caregiver satisfaction in a trauma (acute) care setting.

- The study identified clinical factors that were associated with patient and caregiver satisfaction.

- The study was exploratory and surveys have not been validated in a general trauma population.

patients and their families, the need for satisfaction with communication and the management surrounding end-of-life treatment strategies is evident. ${ }^{56}$ Families often face the burden of becoming surrogate decisionmakers following traumatic injury, must have difficult conversations and can be negatively affected during this experience. ${ }^{7}$ While there is a plethora of research from the past few decades reporting on patient satisfaction following care in oncology, ${ }^{8-10}$ emergency departments, ${ }^{11-14}$ orthopaedic surgery ${ }^{15}$ and in the neuro-intensive care unit (ICU), ${ }^{1}$ there is a paucity of literature on factors influencing both patient and family satisfaction with trauma care.

Although many validated surveys have been suggested to measure patient experiences, including the Hospital Consumer Assessment of Healthcare Providers and Systems (HCAHPS $)^{16}$ or the Quality of Trauma Care Patient-Reported Experience Measure, ${ }^{17}$ these are focused on processes of care and ignore feelings towards delivery of care. Furthermore, these surveys are long and have multiple components, potentially reducing response rates. According to national averages, HCAHPS response rates averaged 27\% in 2017 and have been decreasing. ${ }^{18}$ In addition to measuring experience with processes 
of care, identifying components that drive patient and caregiver satisfaction can help institutions provide highvalue care, as well as improve the relationship between patients and clinicians. ${ }^{19-21}$ As the number of geriatric traumas increases, emphasis is placed on trauma surgeons and their willingness to have honest communication and discussions for goals of care throughout hospitalisation. ${ }^{22}$

The purpose of this study was threefold: (1) to measure and compare satisfaction with trauma care in older adult patients and their caregivers; (2) to identify clinical characteristics associated with patient and caregiver satisfaction; and (3) to identify target areas for quality improvement.

\section{METHODS}

\section{Study design}

This prospective, cross-sectional study included (1) patients who met the Colorado Trauma Registry inclusion criteria (see inclusion criteria at https://www.colorado.gov/pacific/cdphe/trauma-registry-manual) ${ }^{23}$ and were (2) aged $\geq 55$ years. Primary caregivers, family members or legally authorised representatives were also included. Data were collected across three American College of Surgeons (ACS)-verified level I trauma centres in Colorado from November 2016 to December 2017. Patients and caregivers both provided written informed consent prior to being enrolled. If the patient was unable to consent, they could be enrolled by proxy. Patients with severe cognitive impairment were excluded from taking the survey $(n=15)$. Patients with potential cognitive impairment (traumatic brain injuries (TBIs) and/ or a history of dementia, alcohol withdrawal, etc.) had to pass standard hospital cognitive ability screenings prior to taking the survey. Patients with cognitive impairment had the opportunity to be consented by proxy. In order to take the survey, consented patients diagnosed with a TBI had to have passed the Galveston Orientation and Amnesia Test (GOAT), a test to measure baseline cognition in trauma patients. A score of 76-100 is normal, $66-75$ is borderline and $<66$ is impaired; thus, a score on the GOAT of $\leq 66$ indicated failure of TBI screening and exclusion from taking the survey. Patients with a history of dementia and/or had other obvious signs of impairment determined by clinical discretion were asked three simple awareness and orientation $(\mathrm{A} \& \mathrm{O} \times 3)$ questions, and if they answered any question incorrectly they were excluded from taking the survey. A\&O tests dementia and generally included the following questions: patient's full name, location and date. Patients who were consented by proxy and passed the standard screenings were reconsented prior to taking the survey. The assigned proxy still had the opportunity to take the Family Satisfaction with Advanced Cancer Care Scale (FAMCARE) survey even if the patient failed cognitive screenings. Patients without a history of TBI or dementia proceeded to take the survey immediately.
Satisfaction surveys were administered to the patient and their primary caregiver, after the discharge plan was approved and prior to patient exit from the hospital. Patients and their primary caregivers were frequently approached together during trauma rounds to be in the study. Caregiver eligibility was determined by information listed in the patient chart, as well as verbal confirmation by the research coordinator. The research coordinator described the study to the patient and caregiver at this time, invited them to participate, and if in agreement to participate they reviewed and signed the consent forms. After signing, the research coordinators explained they would return to administer the survey when the discharge plan had been approved.

Patients were subject to the usual standard of care at each participating site, which closely followed the ACS Trauma Quality Improvement Program (TQIP) Geriatric Trauma Management Guidelines. ${ }^{24}$ Neither the patient nor the primary caregiver was compensated for participating in this study. The survey was administered through multiple methods to reduce sampling bias (some patients were unable to use tablets and laptops): an electronic tablet, a laptop or was completed by paper, and recorded in SurveyMonkey (Team ADVANTAGE, San Mateo, California) by the study coordinator. Additionally, the results of the survey were not made available to any hospital staff outside of the research team.

\section{Patient and public involvement}

Patients or the public were not involved in the design of the study.

\section{Survey instruments}

The FAMCARE survey has traditionally been used for families of patients with advanced cancer, while the patient is receiving palliative care or after they have passed. The FAMCARE surveys have demonstrated high validity and reliability in several studies and were developed for use in an inpatient setting. ${ }^{8-10} 25-28$ FAMCARE measures the degree of patient, family and caregiver satisfaction with the information provided, availability of hospital staff, physical care management and psychosocial care. Although the FAMCARE satisfaction survey has not been used in a trauma setting, its use has been suggested in other clinical and research settings. ${ }^{8-10} 2529$

Patients and primary caregivers were administered two different satisfaction surveys. Patients were administered the FAMCARE-P13 survey ${ }^{9} 10$ (online supplementary table 1 ), while primary caregivers were administered the FAMCARE survey ${ }^{2628}$ (online supplementary table 2). Each survey is based on a 5-point Likert scale from 1 to 5 : $5=$ very satisfied; $4=$ satisfied; $3=$ undecided; $2=$ dissatisfied; and $1=$ very dissatisfied. Higher scores reflect higher levels of satisfaction. The FAMCARE survey for primary caregivers has 20 questions, equalling a total score range of 1-100. The primary caregivers were asked four additional questions on their background at the end of the survey: (1) What is your age range? (2) What is your gender? (3) 
What was your involvement with the patient's care? (4) What is your relation to the patient? The FAMCARE-P13 is a reduced 13-item version of FAMCARE for patients and has a possible score range of 1-65. The questions in the survey can also be grouped into conceptual structures: information giving, availability of care, physical care and psychosocial care ${ }^{26}$ Additionally, each survey allowed for the respondent to include comments at the conclusion.

\section{Statistical analyses}

To make the FAMCARE scales easier to interpret, both surveys were analysed to include a zero score, creating an overall mean satisfaction rate from $0 \%$ to $100 \%$. Average satisfaction rates were calculated from the total questions answered out of the total questions possible per patient (52 possible points) and per caregiver (80 possible points). Additionally, the score range per question was scaled down from $1-5$ to $0-4$, shifting 0 to "very dissatisfied' and 4 to 'very satisfied'. To analyse satisfaction by proportion of high and low satisfaction scores, we used a cut-off of $\geq 80 \%$ vs $<80 \%$ because it indicates a level of satisfaction that equates to being 'satisfied' to 'very satisfied' with care. Previous studies using the FAMCARE surveys similarly analysed their data. ${ }^{8}{ }^{85}$ Satisfaction by conceptual structures of the surveys was calculated by dividing the questions corresponding to each conceptual category by four.

The analysis performed on this data set was already available for another ongoing study on patient and caregiver satisfaction that was still collecting data to reach the appropriate sample size. The larger prospective, pre-post study involved measuring satisfaction with trauma care before and after publication of the ACS-TQIP Palliative Care Best Practice Guidelines. ${ }^{31}$ We examined the available data and thus a formal sample size calculation was unavailable.

The following covariates were collected on each patient from the trauma registry: sex, age $(55-65,>65)$, race, Injury Severity Score (ISS, 1-15, $\geq 16$ ), hospital length of stay (LOS), ICU LOS, cause of injury (fall vs high acuity vs sport vs other), hospital discharge destination (home/health vs skilled nursing facility vs long-term care vs hospice), and the presence of the following comorbid conditions: a history of mental illness, smoking, dementia, diabetes, chronic obstructive pulmonary disease, hypertension, functionally dependent health status, anticoagulant use, bleeding disorder, congestive heart failure, alcoholism and an advanced directive limiting care.

The following covariates were collected from patient electronic medical records: screening methods for TBI and number of palliative care consults.

The primary outcome variable was overall mean (SD) satisfaction score for patients and caregivers from the FAMCARE-P13 survey and the FAMCARE survey, respectively. The secondary outcomes were the proportion of satisfaction scores $\geq 80 \%$ vs $<80 \%$ and mean satisfaction (SD) scores for each FAMCARE survey question for the patient and the primary caregiver.
Satisfaction and in-hospital patient characteristics and caregiver characteristics were compared univariately between groups of overall satisfaction $<80 \%$ vs $\geq 80 \%$ using $\chi^{2}$ and Fisher's exact tests for categorical variables, and independent samples t-tests and one-way analyses of variance for normally distributed continuous data.

Generalised linear models were used to adjust for differences in overall mean satisfaction by covariate and accounted for clustering by facility Covariate model entry and exit criteria were set to $\mathrm{p}=0.2$ and $\mathrm{p}=0.1$, respectively, for both models. Covariates with $\mathrm{p}$ values greater than 0.2 were not considered in the models, and covariates with $\mathrm{p}$ values greater than 0.1 were automatically removed from the models after adjusting. Covariates available to the patient model included a history of mental illness, alcoholism, smoking and hypertension. Similarly, a patient's history of smoking, bleeding disorder and hypertension were available to the caregiver model.

Stepwise multivariable logistic regression modelling was used to identify independent predictors of satisfaction $\geq 80 \%$ for patients and caregivers. The following covariates were available to the patient model, with an entry criterion of $p=0.2$ and an exit criterion of $p=0.1$ : cause of injury, discharge destination, a history of smoking, hypertension and bleeding disorders. The logistic caregiver model was adjusted for a patient's history of smoking. SAS V.9.4 was used for all analyses. Two-tailed tests with alphas of 0.05 were used for all tests.

\section{RESULTS}

\section{Patient characteristics and satisfaction}

There were 328 patients and 342 caregivers consented and surveyed during the study period. Nine patients and caregivers were excluded because on final review these patients did not meet the Colorado Trauma Registry inclusion criteria. After exclusion, there were 319 patients and 336 caregivers included in the study, and the overall survey response rate was $93 \%$, which was only available across two institutions. The overall mean (SD) satisfaction score for patients was $81.7 \%(15.0 \%)$, indicating that patients were 'satisfied' on average with their care. Table 1 shows the overall mean satisfaction by baseline characteristics of patients who took the survey. Patients who took the survey were predominately female, aged $>65$ years, had hypertension, had an ISS $\leq 15$, a hospital LOS $\leq 4$ days, sustained an injury after a fall and were discharged to an outside facility of care. Patients with a history of smoking had significantly lower satisfaction scores than non-smokers $(70.1 \%(27.0 \%)$ vs $82.8 \%(12.7 \%), \mathrm{p}<0.001$; table 1$)$.

There were 161 patients $(50 \%)$ who had satisfaction $\geq 80 \%$. Table 2 shows the baseline characteristics of patients by satisfaction $<80 \%$ vs $\geq 80 \%$. Compared with the patients who reported satisfaction $<80 \%$, a significantly greater proportion of patients who reported satisfaction $\geq 80 \%$ had sustained an injury after a sport-related accident $(15.0 \%$ vs $5.7 \%, \mathrm{p}=0.02$; table 2$)$. 
Table 1 Overall mean satisfaction by baseline characteristics of patients

\begin{tabular}{|c|c|c|c|}
\hline $\begin{array}{l}\text { Patient } \\
\text { characteristics }\end{array}$ & n (\%) (N=319) & $\begin{array}{l}\text { Mean \% } \\
\text { (SD \%) } \\
\text { satisfaction }\end{array}$ & $P$ value \\
\hline $\operatorname{Sex}^{*}$ & & & 0.28 \\
\hline Male & $148(46.3)$ & $80.7(17.8)$ & \\
\hline Female & $171(53.4)$ & 82.5 (12.0) & \\
\hline Age, years & & & 0.87 \\
\hline $55-65$ & $92(28.8)$ & $81.4(14.7)$ & \\
\hline$>65$ & $228(71.3)$ & $81.8(15.1)$ & \\
\hline $\begin{array}{l}\text { Injury Severity } \\
\text { Score }\end{array}$ & & & 0.26 \\
\hline $1-15$ & $282(88.1)$ & $82.0(14.0)$ & \\
\hline$\geq 16$ & $36(11.3)$ & 79.1 (21.0) & \\
\hline $\begin{array}{l}\text { Hospital LOS, } \\
\text { days }\end{array}$ & & & 0.17 \\
\hline$\leq 4$ & 165 (51.6) & $82.8(13.2)$ & \\
\hline$>4$ & $155(48.4)$ & $80.5(16.7)$ & \\
\hline ICU stay & & & 0.86 \\
\hline Yes & $115(35.9)$ & $81.9(15.2)$ & \\
\hline No & 205 (64.0) & $81.6(14.9)$ & \\
\hline Cause of injury $†$ & & & 0.61 \\
\hline Fall & 231 (72.2) & $81.3(14.4)$ & \\
\hline High acuity & $49(15.3)$ & 81.9 (17.9) & \\
\hline Sport & 33 (10.3) & 84.8 (13.9) & \\
\hline Other & $7(2.2)$ & 79.0 (17.6) & \\
\hline $\begin{array}{l}\text { Hospital discharge } \\
\text { destination } \ddagger\end{array}$ & & & 0.55 \\
\hline $\begin{array}{l}\text { Home/home } \\
\text { health }\end{array}$ & $144(45.0)$ & $82.7(14.5)$ & \\
\hline $\begin{array}{l}\text { Rehabilitation/ } \\
\text { SNF/LTC }\end{array}$ & $170(53.1)$ & $81.1(14.3)$ & \\
\hline Hospice/AMA & $3(0.9)$ & $77.0(24.1)$ & \\
\hline
\end{tabular}

Comorbidities (yes
vs no)

\begin{tabular}{|c|c|c|c|}
\hline Smoker & $29(9.1)$ & 70.1 (27.0) & $<0.001$ \\
\hline Diabetes & 53 (16.6) & 80.3 (21.1) & 0.46 \\
\hline Dementia & $13(4.1)$ & $79.2(9.4)$ & 0.55 \\
\hline Mental illness & $36(11.3)$ & 78.3 (12.6) & 0.15 \\
\hline COPD & $31(9.7)$ & $82.4(15.3)$ & 0.78 \\
\hline Hypertension & 164 (51.3) & 83.6 (12.7) & 0.03 \\
\hline $\begin{array}{l}\text { Functionally } \\
\text { dependent } \\
\text { health status }\end{array}$ & $22(6.9)$ & $83.4(10.2)$ & 0.56 \\
\hline Anticoagulant & $23(7.2)$ & 83.8 (11.2) & 0.48 \\
\hline $\begin{array}{l}\text { Bleeding } \\
\text { disorder }\end{array}$ & $13(4.1)$ & 84.5 (12.3) & 0.49 \\
\hline $\begin{array}{l}\text { Congestive } \\
\text { heart failure }\end{array}$ & $13(4.1)$ & $82.6(12.7)$ & 0.83 \\
\hline
\end{tabular}

Continued
Table 1 Continued

\begin{tabular}{llll}
\hline $\begin{array}{l}\text { Patient } \\
\text { characteristics }\end{array}$ & $\mathbf{n}(\%)$ (N=319) & $\begin{array}{l}\text { Mean \% } \\
\text { (SD \%) } \\
\text { satisfaction }\end{array}$ & P value \\
\hline \multicolumn{1}{|l}{ Alcoholism } & $12(3.8)$ & $75.8(14.2)$ & 0.17 \\
$\begin{array}{l}\text { Advanced } \\
\text { directive limiting } \\
\text { care }\end{array}$ & $13(4.1)$ & $81.3(11.3)$ & 0.94 \\
$\begin{array}{l}\text { Traumatic brain } \\
\text { injury§ }\end{array}$ & $77(24.1)$ & $81.5(16.2)$ & 0.91 \\
$\begin{array}{l}\text { Palliative care } \\
\text { consult }\end{array}$ & $38(11.9)$ & $81.0(11.9)$ & 0.78 \\
\hline
\end{tabular}

*Missing 1.

†High acuity includes pedestrian vs car accidents, car crash/rollover injuries, and gunshot wounds. Others include animal bites, environmental and other.

‡Missing 2.

§Missing 2.

AMA, against medical advice; COPD, chronic obstructive pulmonary disease; ICU, intensive care unit; LOS, length of stay; LTC, long-term care; SNF, skilled nursing facility.

The generalised linear model identified patients with a history of smoking as the single independent predictor of overall mean satisfaction. After adjusting, patients with a history of smoking had significantly lower overall mean satisfaction $(69.7 \%$ vs $79.3 \%, p=0.008)$ compared with non-smokers. No other covariates were significant after adjusting.

Discharge home versus discharge to an outside care facility was identified as an independent predictor of satisfaction $\geq 80 \%$. After adjusting, patients had a 1.6fold increased odds of satisfaction $\geq 80 \%$ if they were discharged home compared with an outside facility (95\% CI 1.0 to $2.4, \mathrm{p}=0.048$ ). No other covariates remained in the patient model after adjusting.

\section{Primary caregiver characteristics and satisfaction}

The overall mean (SD) satisfaction score for caregivers was $83.6 \%(13.4 \%)$, suggesting that caregivers were 'satisfied' on average with the care the patient received. Caregivers were often women, aged 55-74 years, 'very involved' in their patient's care and were spouses of the patient (table 3). There were 181 caregivers (54\%) who had satisfaction scores $\geq 80 \%$, with no significant differences observed between satisfaction groups (online supplementary table 3 ).

The generalised linear model for caregivers showed similar results to patients: patients with a history of smoking was an independent predictor of having significantly lower overall mean caregiver satisfaction $(77.8 \%$ vs $85.0 \%, \mathrm{p}=0.01$ ), compared with families of patients who were non-smokers.

No independent predictors of caregiver satisfaction $\geq 80 \%$ were identified for inclusion in the caregiver logistic regression model (see online supplementary table 4 for adjusted models for patient and caregiver satisfaction). 
Table 2 Baseline characteristics of patients by satisfaction $<80 \%$ vs $\geq 80 \%$

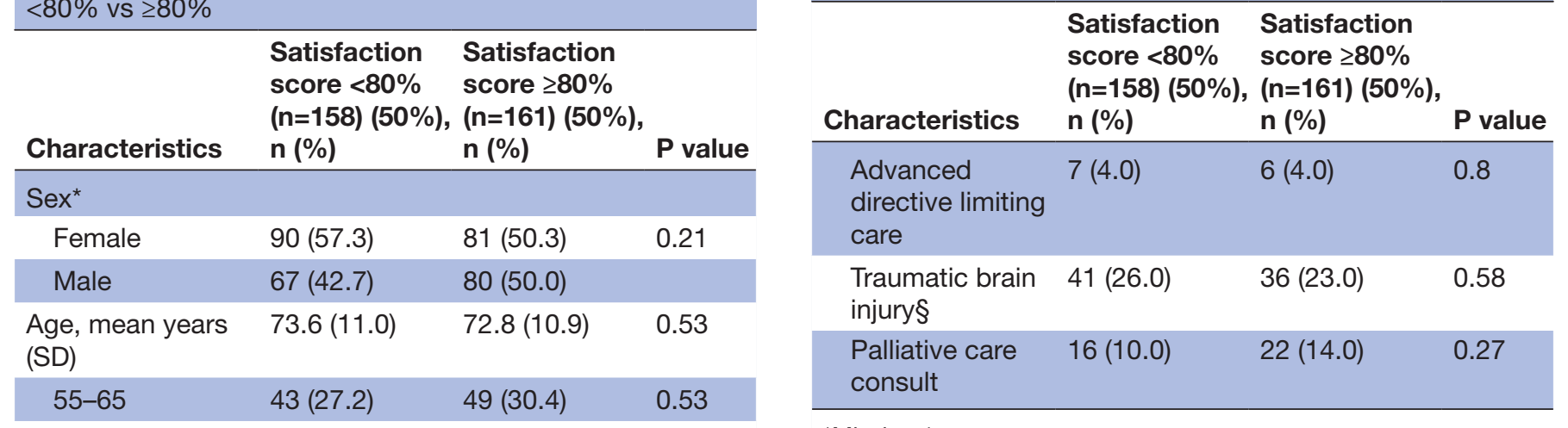

\begin{tabular}{llll}
\multicolumn{5}{c}{$55-65$} & $43(27.2)$ & $49(30.4)$ & 0.53 \\
\multicolumn{1}{c}{65} & $115(72.8)$ & $112(70.0)$ & \\
Race (white) & $146(92.0)$ & $146(90.7)$ & 0.58 \\
$\begin{array}{l}\text { Injury Severity } \\
\text { Score, median } \\
\text { (IQR) }\end{array}$ & $9.0(5-10)$ & $9.0(5-10)$ & 0.75 \\
& & &
\end{tabular}

(IQR)

\begin{tabular}{|c|c|c|c|}
\hline $1-15$ & $140(88.6)$ & $141(87.6)$ & 0.78 \\
\hline$\geq 16$ & $18(11.4)$ & $20(12.4)$ & \\
\hline $\begin{array}{l}\text { Hospital LOS, } \\
\text { median (IQR) days }\end{array}$ & $5.0(4-6)$ & $4.0(3-6)$ & 0.48 \\
\hline $\begin{array}{l}\text { ICU LOS, median } \\
\text { (IQR) days }\end{array}$ & $2.0(2-3)$ & $2.0(2-3)$ & 0.2 \\
\hline n (\%) & $56(35.4)$ & $59(36.7)$ & 0.82 \\
\hline Cause of injury $†$ & & & 0.02 \\
\hline Fall & $122(77.2)$ & $108(67.1)$ & \\
\hline High acuity & $22(13.9)$ & $27(16.8)$ & \\
\hline Sport & $9(5.7)$ & $24(15.0)$ & \\
\hline Other & $5(3.2)$ & $2(1.2)$ & \\
\hline $\begin{array}{l}\text { Hospital discharge } \\
\text { destination } \neq\end{array}$ & & & 0.13 \\
\hline $\begin{array}{l}\text { Home/home } \\
\text { health }\end{array}$ & $63(40.0)$ & $81(50.9)$ & \\
\hline Rehab/SNF/LTC & 93 (58.9) & 77 (48.4) & \\
\hline Hospice/AMA & $2(1.3)$ & $1(0.6)$ & \\
\hline \multicolumn{4}{|l|}{ Comorbidities } \\
\hline Mental illness & $17(11.0)$ & $19(12.0)$ & 0.68 \\
\hline Smoker & $10(6.2)$ & $18(11.4)$ & 0.1 \\
\hline Dementia & $5(3.1)$ & $8(5.1)$ & 0.38 \\
\hline Diabetes & $28(17.0)$ & $24(15.2)$ & 0.59 \\
\hline COPD & $15(9.3)$ & $16(10.1)$ & 0.81 \\
\hline Hypertension & $90(56.0)$ & $74(47.0)$ & 0.11 \\
\hline $\begin{array}{l}\text { Functionally } \\
\text { dependent } \\
\text { health status }\end{array}$ & $10(6.0)$ & $12(8.0)$ & 0.63 \\
\hline Anticoagulant & $13(8.1)$ & $10(6.3)$ & 0.55 \\
\hline $\begin{array}{l}\text { Bleeding } \\
\text { disorder }\end{array}$ & $9(6.0)$ & $4(3.0)$ & 0.17 \\
\hline $\begin{array}{l}\text { Congestive heart } \\
\text { failure }\end{array}$ & $6(4.0)$ & $7(4.4)$ & 0.75 \\
\hline Alcoholism & $5(3.1)$ & $7(4.4)$ & 0.53 \\
\hline
\end{tabular}

Table 2 Continued

*Missing 1.

†Others included bike, motorcycle accident, motor vehicle accident, skiing and so on.

‡Missing 2.

§Missing 2.

AMA, against medical advice; COPD, chronic obstructive pulmonary disease; ICU, intensive care unit; LOS, length of stay; LTC, long-term care; SNF, skilled nursing facility.

\section{Patient and caregiver satisfaction by survey question and structure}

There were 246 patient and caregiver pairs who took the surveys. Across conceptual structures of satisfaction with care for patients overall, patients had lowest scores on information giving $(80.4 \%, 14.7 \%)$ and highest scores on psychosocial care $(85.4 \%, 16.0 \%)$. Caregivers also reported lowest satisfaction with information giving $(80.9 \%, 15.0 \%)$ and highest satisfaction with psychosocial care $(86.9 \%, 15.4 \%)$. There were no significant differences observed between patients and primary caregivers by overall conceptual structures. When analysing by mean scores of paired questions between surveys (table 4), patients and caregivers tended to respond the same way, with the exception of 'availability of nurses to answer questions' and 'speed with which symptoms were treated' (table 4), where caregivers had significantly higher satisfaction for both questions compared with patients. There were no other significant differences observed by question between patients and caregivers.

\section{DISCUSSION}

Traumatic injuries can be a tragic event, especially for older adult patients and their families, who often need to make challenging decisions about end-of-life care quickly. The quality of the hospital experience during these difficult times can be measured through satisfaction of treatment for patients and their families together. In this multicentre study of over 300 trauma patients and their caregivers, we identified patient-specific clinical factors that drive satisfaction and that patients and caregivers frequently had similar individual and aggregate responses. Better understanding of patient and caregiver characteristics may help us tailor trauma care support for older adult patients and their caregivers. 


\begin{tabular}{|c|c|c|c|}
\hline $\begin{array}{l}\text { Caregiver } \\
\text { characteristics }\end{array}$ & n (\%) (N=336) & $\begin{array}{l}\text { Mean } \\
\text { satisfaction \% } \\
\text { (SD \%) }\end{array}$ & $P$ value \\
\hline Sex ${ }^{*}$ & & & 0.36 \\
\hline Male & 117 (34.8) & $84.5(12.1)$ & \\
\hline Female & $213(63.4)$ & 83.1 (14.2) & \\
\hline Age range, years $\dagger$ & & & 0.74 \\
\hline $18-34$ & $7(2.1)$ & $80.0(8.6)$ & \\
\hline $35-54$ & $63(18.8)$ & 82.5 (13.9) & \\
\hline $55-74$ & $165(49.1)$ & $84.2(12.4)$ & \\
\hline$\geq 75$ & 99 (29.5) & $83.7(15.1)$ & \\
\hline $\begin{array}{l}\text { Involvement in } \\
\text { patient's care }\end{array}$ & & & 0.3 \\
\hline Uninvolved & $1(0.3)$ & $65.0(-)$ & \\
\hline Very uninvolved & $19(5.7)$ & $85.1(22.7)$ & \\
\hline Involved & $35(10.4)$ & $80.9(12.8)$ & \\
\hline Very involved & $271(80.7)$ & $83.8(12.5)$ & \\
\hline Relation to patient & & & 0.81 \\
\hline Spouse & 135 (40.2) & 83.5 (14.5) & \\
\hline Daughter & $85(25.3)$ & $82.8(13.0)$ & \\
\hline Son & 50 (14.9) & 83.8 (12.8) & \\
\hline $\begin{array}{l}\text { Significant } \\
\text { other }\end{array}$ & $15(4.5)$ & $84.7(14.1)$ & \\
\hline Sister & 13 (3.9) & $90.2(10.6)$ & \\
\hline $\begin{array}{l}\text { Power of } \\
\text { attorney }\end{array}$ & $7(2.1)$ & $82.6(10.0)$ & \\
\hline Other§ & $30(8.6)$ & 83.5 (13.0) & \\
\hline
\end{tabular}

*Sex missing 4.

†Age range missing 1.

łlnvolvement missing 8.

§Other included brother, nephew, friend, granddaughter and father.

Furthermore, we observed that mean (SD) satisfaction with psychosocial care ('The way family was included in treatment and care decisions') was the highest scored conceptual structure for both patients and their caregivers $(85.4 \%(16.0 \%)$ vs $86.9 \%(15.4 \%)$ respectively). We believe higher satisfaction with psychosocial support compared with other domains of care was the result of the availability of spiritual and bereavement support services provided by chaplains, social workers and spiritual care members of our trauma team. Advanced directive discussions, proxy assignments, as well as informal family meetings and goals of care discussions were well established as part of the ACS TQIP Geriatric Trauma Management Guidelines across the participating hospitals. According to several anecdotal comments made at the end of the surveys, patients and caregivers were very satisfied with the high level of respect, support and inclusion in decisionmaking for all parties. Although we can speculate what aspects of care these refer to, it is challenging to directly measure which care interventions correlate with satisfaction. Many studies have shown that satisfaction with care can be influenced by factors relating to a patient's demographic and clinical characteristics, ${ }^{32} 33$ such as age, ${ }^{34}$ insurance status ${ }^{12}$ and mental health. ${ }^{35}$ Other components of satisfaction have been tied to accessibility of care, communication and decision-making, emotional support, coordination of care, pain management, and psychological health; however, an agreed on consensus has yet to be reached. $^{3-5} 1532$ 36-39 We observed that satisfaction was related to some elements of a patient's clinical status, as well as communication of information, availability and coordination of care, and symptom management.

Our survey captured similar metrics of satisfaction with care, compared to published literature in various patient populations. 4363840 Rogers and colleagues compared satisfaction between trauma and general surgery patients using the Press-Ganey Patient Satisfaction Questionnaire. ${ }^{39}$ Survey sections included physician performance (PP) and general performance (GP) questions and were analysed by mean overall satisfaction, with some similar questions to the FAMCARE surveys used in the current study. The overall mean satisfaction of PP for trauma patients was $81.0 \%$ (19.5) and was $84.0 \%$ (13.0) for the GP section. We reported similar trauma patient overall satisfaction of $81.7 \%(15.0 \%)$ and $81.5 \%(15.2 \%)$ for the most closely related section to PP, 'Physical Care'. However, surveys were analysed differently, satisfaction scores were not broken down by question, and more questions on the Press-Ganey survey were about various hospital characteristics. Heyland et al administered a satisfaction survey tailored to family members of patients in the ICU and also collected similar factors of satisfaction as our study. ${ }^{36}$ Family members reported a mean (SD) overall satisfaction with care of $84.3 \%(15.7 \%), 89.0 \%(16.5 \%)$ for coordination of care, $70.7 \%(20.9 \%)$ for physician communication and $77.5 \%(25.8 \%)$ with consistency of information. ${ }^{31}$ We had a similar mean score for caregiver satisfaction with overall care $(83.6 \%(13.4 \%))$, yet lower values for coordination of care $(84.5 \%(17.4 \%))$ and only slightly higher values for physician communication or 'availability of doctors to the family' (82.1\% (16.5\%)).

There is a lack of published literature on studies comparing patient satisfaction with family satisfaction in a general trauma population. In an article by Gade et al, satisfaction scores were compared between an inpatient interdisciplinary palliative care service and traditional hospital care in the ICU. ${ }^{33}$ The study used the Modified City of Hope Patient Questionnaire, which measured patient and caregiver satisfaction with care in domains of patient management and symptom relief, psychological and social support, and communication, with higher scores indicating greater satisfaction. The palliative care service group reported a $73 \%$ satisfaction level for communication by patients and caregivers. ${ }^{36}$ Although we used a different measurement scale, we also found lower satisfaction scores for exchange of information between clinicians, patients and caregivers. Aligning with our 
Table 4 Satisfaction by survey question between patient and caregiver pairs, $n=246$

\section{Conceptual structure, item}

Information giving Information provided about patient's prognosis

Information given about how to manage pain

Information given about patient's tests and treatments

Information given about side effects

Answers from health professionals
Patient mean \% (SD

$\%)$

$79.9(18.7)$
$79.4(18.4)$
$81.8(17.4)$
$77.5(19.0)$
$83.7(17.1)$

Caregiver mean \% (SD $\%)$

$P$ value

$82.7(16.3)$

$78.8(20.1)$

83.5 (16.6)

$76.3(20.6)$

$83.3(16.3)$
0.08

0.74

0.26

0.51

0.79

Availability of care

Availability of nurses to answer questions

$84.5(15.3)$

$87.4(14.8)$

0.02

Availability of doctors to answer questions

$82.2(18.3)$

$82.1(16.6)$

0.93

Availability of doctor to the family

$82.1(16.5)$

Availability of a hospital bed

$-$

$-\quad 89.5(14.9)$

$-$

$-$

\section{Physical care}

How thoroughly doctor assessed symptoms

Speed with which symptoms were treated

The patient's pain relief

The way tests and procedures were performed

Referrals to specialists

The way tests and treatments are followed up by the doctor

Time required to make a diagnosis

$\begin{array}{lll}83.3(17.1) & 83.6(16.5) & 0.83 \\ 80.6(17.9) & 84.0(17.0) & 0.03 \\ - & 78.5(16.8) & - \\ 82.1(17.6) & 83.6(15.7) & 0.33 \\ 79.9(17.9) & 79.9(17.6) & 0.99 \\ 80.7(17.5) & 82.3(16.5) & 0.32 \\ - & 85.1(16.6) & -\end{array}$

\section{Psychosocial care}

The way family was included in treatment and care decisions

Family conferences held to discuss patient's illness

Coordination of care

Doctor's attention to patient's description of symptoms

$85.4(16.0)$
-
-
-

$86.9(15.4)$

0.29

$82.7(16.9)$

$-$

$84.5(17.4)$

$84.3(16.2)$

$-$

-, Indicates no related question on the patient survey.

findings, other studies on satisfaction also indicate that communication between clinicians, patients and families, as well as coordination of care, often have lower satisfaction scores compared to satisfaction with emotional support for patients and families, pain management, and frequency of care. ${ }^{173336}$

Challenges with communication in patient care are not unexpected, and the effects of these communication challenges were observed in our data. We observed that the top 3 areas for improvement in satisfaction for both patients and caregivers fell under the information giving conceptual structure. These three communication areas pertained to (ordered from lowest to highest) information provided about side effects, pain management and patients' prognosis. The similarities between the scores indicate that the satisfaction of both patients and caregivers was similarly affected by non-optimal communication. Furthermore, anecdotal evidence gathered from the surveys suggested that patients and their caregivers were frequently receiving inconsistent or confusing information from multiple clinical providers.

Interestingly, we observed that patients with a history of smoking had significantly lower overall mean satisfaction. Additionally, we found that patients who were discharged to an outside facility of care (compared to patients discharged home) were significantly more likely to report lower satisfaction with care. Although satisfaction can be challenging to predict, patients with a history of hypertension tended to be significantly older and frequently did not have a caregiver present, while patients with a history of smoking tended to also have a history of alcoholism and mental illness, and experienced drug and alcohol withdrawal. Patients who were discharged to an outside facility had a significantly longer hospital LOS than patients who were discharged home. Thus, patients with a history of smoking became a proxy for a sicker group, 
which may have perceived a more negative hospital experience and reported lower satisfaction. This is in line with prior research, showing that a patient's hospital experience can be influenced by health and proxy status. ${ }^{41}{ }^{42}$

We also found that individual caregiver characteristics (sex, age range, level of involvement or relation) did not help predict caregiver satisfaction. Caregiver satisfaction was influenced by characteristics of the patient that they cared for, including a history of smoking or dementia. Significantly more family members were 'very uninvolved' with the patients who had a history of smoking. The caregivers may have also been influenced by the state of the patient.

These characteristics may be important pieces in understanding how to best tailor delivery of care. Older trauma patients who have a complicated medical history or do not appear to have responsible assistance from a caregiver could be a flag for clinicians to do their due diligence in understanding patient needs and delivering the best care. Furthermore, clinicians and other responsible staff should be targeting prolonged hospital stay with patients discharged to outside facilities as both a performance and patient-specific issue.

\section{Limitations}

This study has several limitations. First, the patients and caregivers responding to the satisfaction surveys may not have been representative of the general population seen across our facilities. Patients who were 'very dissatisfied' or 'undecided' may have withheld from taking the survey. Second, healthcare surveys administered in person can sometimes artificially inflate the results because patients or caregivers might believe their survey results will negatively impact the care received. However, by capturing satisfaction results soon before hospital discharge and without disclosing them to treating staff, we hoped to obtain a more accurate and unbiased description of patient and caregiver satisfaction. Third, we could not link specific in-hospital interventions with satisfaction scores but hope to collect these data points in future studies. Fourth, because this was a cross-sectional study of three hospitals, other centres with different populations and goals of care may not observe the same satisfaction scores; nonetheless, our inclusion of a general, older adult trauma population may help with applicability to other sites hoping to understand patient and family satisfaction. Fifth, because this was an exploratory study, the FAMCARE surveys used were not previously validated in a trauma population and additional work may be needed to verify the results using an instrument tailored for this population. Sixth, we were not able to collect response rates from one of the trauma centres. Lastly, families of patients who died in-hospital were not approached to be in the study.

\section{CONCLUSIONS}

This study serves as a quality improvement initiative to identify the strengths and weaknesses of patient and family delivery of care in a general, older adult trauma population. We showed congruence of satisfaction with trauma between patients and their primary caregivers, allowing for the potential of a proxy for assessing care in critical trauma care settings. Although we reported that most patients and their caregivers were 'satisfied' with their trauma care, there is opportunity for improvement in communication tactics and coordination of care among patients and their families, as well as targeting patients and caregivers of patients who may have a complicated medical history. Addressing these deficiencies will include closing the communication loop internally among clinicians, physician assistants, and nurses. These improvements should eventually help to raise patient and caregiver satisfaction and create a better overall hospital experience.

\section{Author affiliations}

${ }^{1}$ Trauma Services Department, St. Anthony's Hospital, Lakewood, Colorado, USA ${ }^{2}$ Trauma Research Department, St Anthony Hospital, Lakewood, Colorado, USA

${ }^{3}$ Trauma Research Department, Swedish Medical Center, Englewood, Colorado, USA ${ }^{4}$ Trauma Research Department, Penrose Hospital, Colorado Springs, Colorado, USA

${ }^{5}$ Trauma Services Department, Swedish Medical Center, Englewood, Colorado, USA

${ }^{6}$ Trauma Services Department, Penrose Hospital, Colorado Springs, Colorado, USA

Acknowledgements The authors would like to thank the clinical study coordinators, Diane Redmond, RN, MSN, and Jennifer Pekarek, RN, BSN, CCRP, for their invaluable work in implementing this study, continuing to carry it forward and their enthusiasm on the subject area.

Contributors All authors provided final approval of the submitted manuscript and agree to be accountable for all aspects of the work in ensuring that questions related to the accuracy or integrity of any part of the work are appropriately investigated and resolved. RV is responsible for study conception, literature review, interpretation of the data and critical revisions. CM is responsible for literature review, design, data acquisition, data analysis and interpretation, and drafting the manuscript. $\mathrm{AO}$ is responsible for design, data interpretation and critical revisions. $\mathrm{PB}, \mathrm{CD}$ and $\mathrm{AT}$ are responsible for interpretation of the data and critical revisions. NL is responsible for interpretation of the data and critical revisions. LP is responsible for data acquisition, interpretation of the data and critical revision. DB-0 is responsible for interpretation of the data and critical revisions.

Funding The authors have not declared a specific grant for this research from any funding agency in the public, commercial or not-for-profit sectors.

Competing interests None declared.

Patient consent for publication Obtained.

Ethics approval Ethical approval in accordance with the Declaration of Helsinki was obtained from the institutional review board at all participating sites before data collection (Hospital Corporation of America IRB\# 980028, Catholic Health IRB\# 1023525 and 975918). All participants were informed about the purpose and nature of this study, and provided written informed consent to be considered for participation in the study.

Provenance and peer review Not commissioned; externally peer reviewed. Data availability statement Data are available upon reasonable request.

Open access This is an open access article distributed in accordance with the Creative Commons Attribution Non Commercial (CC BY-NC 4.0) license, which permits others to distribute, remix, adapt, build upon this work non-commercially, and license their derivative works on different terms, provided the original work is properly cited, appropriate credit is given, any changes made indicated, and the use is non-commercial. See: http://creativecommons.org/licenses/by-nc/4.0/.

ORCID iD

David Bar-Or http://orcid.org/0000-0002-3685-314X 


\section{REFERENCES}

1 Hwang DY, Yagoda D, Perrey HM, et al. Assessment of satisfaction with care among family members of survivors in a neuroscience intensive care unit. J Neurosci Nurs 2014;46:106-16.

2 Mosenthal AC, Murphy PA, Barker LK, et al. Changing the culture around end-of-life care in the trauma intensive care unit. J Trauma 2008;64:1587-93.

3 Lai VKW, Lee A, Leung P, et al. Patient and family satisfaction levels in the intensive care unit after elective cardiac surgery: study protocol for a randomised controlled trial of a preoperative patient education intervention. BMJ Open 2016;6:e011341.

4 É A, Sprung CL. Family-physician interactions in the intensive care unit. Crit Care Med 2004;32:2323-8.

5 Azoulay E, Chevret S, Leleu G, et al. Half the families of intensive care unit patients experience inadequate communication with physicians. Crit Care Med 2000;28:3044-9.

6 Stapleton RD, Engelberg RA, Wenrich MD, et al. Clinician statements and family satisfaction with family conferences in the intensive care unit*. Crit Care Med 2006;34:1679-85.

7 Manskow US, Arntzen C, Damsgård E, et al. Family members' experience with in-hospital health care after severe traumatic brain injury: a national multicentre study. BMC Health Serv Res 2018;18:951.

8 Ringdal GI, Jordhøy MS, Kaasa S. Measuring quality of palliative care: psychometric properties of the FAMCARE scale. Qual Life Res 2003;12:167-76.

9 Lo C, Burman D, Hales S, et al. The FAMCARE-Patient scale: measuring satisfaction with care of outpatients with advanced cancer. Eur J Cancer 2009;45:3182-8.

10 Parpa E, Galanopoulou N, Tsilika E, et al. Psychometric Properties of the Patients' Satisfaction Instrument FAMCARE-P13 in a Palliative Care Unit. Am J Hosp Palliat Care 2016;1049909116645511.

11 Boudreaux ED, Friedman J, Chansky ME, et al. Emergency department patient satisfaction: examining the role of acuity. Acad Emergency Med 2004;11:162-8.

12 Boudreaux ED, Ary RD, Mandry CV, et al. Determinants of patient satisfaction in a large, municipal ED: the role of demographic variables, visit characteristics, and patient perceptions. Am J Emerg Med 2000;18:394-400.

13 Boudreaux ED, Mandry CV, Wood K. Patient satisfaction data as a quality indicator: a tale of two emergency departments. Acad Emerg Med 2003;10:261-8.

14 Boudreaux ED, O'Hea EL. Patient satisfaction in the emergency department: a review of the literature and implications for practice. $J$ Emerg Med 2004;26:13-26.

15 Harris IA, Dao ATT, Young JM, et al. Predictors of patient and surgeon satisfaction after orthopaedic trauma. Injury 2009;40:377-84.

16 Mann RK, Siddiqui Z, Kurbanova N, et al. Effect of HCAHPS reporting on patient satisfaction with physician communication. $J$. Hosp. Med. 2016;11:105-10.

17 Bobrovitz N, Santana MJ, Kline T, et al. Multicenter validation of the quality of trauma care patient-reported experience measure (QTACPREM). J Trauma Acute Care Surg 2016;80:111-8.

18 Godden E, Paseka A, Gnida J, et al. The impact of response rate on HCAHPS dimension scores. Patient Experience Journal 2019;6:105-14.

19 Singer ES, Merritt RE, D'Souza DM, et al. Patient satisfaction after lung cancer surgery: do clinical outcomes affect HCAHPS scores? Ann Thorac Surg. In Press 2019.

20 Lyu $\mathrm{H}$, Wick EC, Housman M, et al. Patient satisfaction as a possible indicator of quality surgical care. JAMA Surg 2013;148:362-7.

21 Chiou S-J, Lee P-C, Chang Y-H, et al. Assessment of patient experience profiles and satisfaction with expectations of treatment effects by using latent class analysis based on a national patient experience survey in Taiwan. BMJ Open 2019;9:e023045.
22 Adams SD, Holcomb JB. Geriatric trauma. Curr Opin Crit Care 2015;21:520-6.

23 Trauma Registry Manual Inclusion Criteria: Level I-III. Colorado Department of Public Health \& Environment, 2019. Available: https:// www.colorado.gov/pacific/cdphe/trauma-registry-manual [Accessed 10 sep 2019].

24 ACS TQIP Geriatric Trauma Management Guidelines. American College of surgeons Committee on trauma. Chicago, IL: American College of Surgeons, 2012. https://www.facs.org/-/media/files/ quality-programs/trauma/tqip/geriatric_guidelines.ashx?la=en

25 Lo C, Burman D, Rodin G, et al. Measuring patient satisfaction in oncology palliative care: psychometric properties of the FAMCAREpatient scale. Qual Life Res 2009;18:747-52.

26 Kristjanson LJ. Validity and reliability testing of the FAMCARE scale: measuring family satisfaction with advanced cancer care. Soc Sci Med 1993;36:693-701

27 Aoun S, Bird S, Kristjanson LJ, et al. Reliability testing of the FAMCARE-2 scale: measuring family carer satisfaction with palliative care. Palliat Med 2010;24:674-81.

28 Kataoka-Yahiro MR, McFarlane S, Kealoha M, et al. Asian and native Hawaiian family caregiver satisfaction with palliative care services in nursing homes. Int J Palliat Nurs 2016;22:141-9.

29 Dudgeon DJ, Knott C, Eichholz M, et al. Palliative care integration project (PCIP) quality improvement strategy evaluation. $J$ Pain Symptom Manage 2008;35:573-82.

30 Beaumont CB, Nekolaichuk CP. FAMCARE and FAMCARE-2 guidelines palliative and end-of-life Institute, 2012. Available: http:// www.palliative.org/NewPC/_pdfs/tools/FAMCARE\%20Guidelines15Aug12.pdf [Accessed 1 Aug 2016].

31 ACS TQIP Palliative Care Best Practice Guidelines. Acs TQIP: trauma quality improvement program, 2017. Available: https://www.facs. org/-/media/files/quality-programs/trauma/tqip/palliative_guidelines. ashx?la=en [Accessed 12 Sep 2019].

32 Marcinowicz L, Chlabicz S, Grebowski R. Patient satisfaction with healthcare provided by family doctors: primary dimensions and an attempt at typology. BMC Health Serv Res 2009;9:63.

33 Gade G, Venohr I, Conner D, et al. Impact of an inpatient palliative care team: a randomized controlled trial. J Palliat Med 2008;11:180-90.

34 Welch SJ. Twenty years of patient satisfaction research applied to the emergency department: a qualitative review. Am J Med Qual 2010;25:64-72.

35 Michaels AJ, Michaels CE, Smith JS, et al. Outcome from injury: general health, work status, and satisfaction 12 months after trauma. $J$ Trauma 2000;48:841-50.

36 Heyland DK, Rocker GM, Dodek PM, et al. Family satisfaction with care in the intensive care unit: results of a multiple center study*. Crit Care Med 2002;30:1413-8.

37 Azoulay E, Pochard F, Chevret S, et al. Impact of a family information leaflet on effectiveness of information provided to family members of intensive care unit patients: a multicenter, prospective, randomized, controlled trial. Am J Respir Crit Care Med 2002;165:438-42.

38 Jacobowski NL, Girard TD, Mulder JA, et al. Communication in critical care: family rounds in the intensive care unit. American Journal of Critical Care 2010;19:421-30.

39 Rogers FB, Krasne M, Bradburn E, et al. Acute care and trauma surgeons: we can't get no satisfaction--what do satisfaction surveys measure? Am Surg 2012;78:731-4.

40 Malacrida R, Bettelini CM, Degrate A, et al. Reasons for dissatisfaction: a survey of relatives of intensive care patients who died. Crit Care Med 1998;26:1187-93.

41 Elliott MN, Lehrman WG, Goldstein E, et al. Do hospitals RANK differently on HCAHPS for different patient subgroups? Med Care Res Rev 2010;67:56-73.

42 Elliott MN, Lehrman WG, Beckett MK, et al. Gender differences in patients' perceptions of inpatient care. Health Serv Res 2012;47:1482-501. 